\title{
Sweet's syndrome associated with Crohn's disease*
}

\author{
Caren dos Santos Lima ${ }^{1}$ \\ Heliana Freitas de Oliveira Góes ${ }^{1}$ \\ Enoi Aparecida Guedes Vilar ${ }^{2}$
}

\author{
Roberta Duarte Bezerra Pinto ${ }^{1}$ \\ Simone de Abreu Neves Salles ${ }^{1}$ \\ Carla dos Santos Lima ${ }^{3}$
}

DOI: http:/ /dx.doi.org/10.1590/abd1806-4841.20175298

\begin{abstract}
Sweet's syndrome is an uncommon benign skin disorder, whose pathogenesis remains unknown. Its classic form is more common in women and presents itself as papular-nodular, painful and erythematous or violaceous lesions. It mainly affects the face, neck, and upper limbs. Fever and neutrophilic leukocytosis are also common features. Although it is considered a systemic disease marker in more than half of patients, the association of this condition with Crohn's disease is rare, with few cases reported in the literature, of which, none in Brazil. We report the case of a patient with Crohn's disease who developed the classical features of Sweet's syndrome.
\end{abstract}

Keywords: Crohn's disease; Neutrophil infiltration; Sweet's syndrome

\section{INTRODUCTION}

Sweet's syndrome (SS), also known as acute febrile neutrophilic dermatosis, is an uncommon skin disorder of unknown origin characterized by the sudden appearance of painful erythematous lesions (papules, plaques, and nodules) accompanied by fever and neutrophilia. ${ }^{1,2}$ It is generally associated with other diseases, such as infections, inflammatory diseases, connective tissue diseases, and cancer. ${ }^{1,3}$ However, its association with Crohn's disease (CD) is rare, with only 40 cases reported in the literature. ${ }^{3}$ A systematic review published in 2002 revealed no reports of this association in Brazil. ${ }^{4}$ We report a case of a patient in which the onset of SS coincided with the first episode of CD.

\section{CASE REPORT}

We report a 39-year-old dark-skinned female patient from Natal (RN) presented with diarrhea with small amount of mucous and bloody discharge 8 months previously (5 episodes/day). The symptoms were accompanied by diffuse abdominal pain, weight loss, fever and generalized arthralgia. Concomitantly, we observed infiltrated nonpruritic round erythematous-violaceous plaques, some with mammillated surface, measuring $0.5-2.0 \mathrm{~cm}$ in diameter. The lesions were distributed on the upper trunk, back, upper limbs and palms. The patient sought dermatological care and a specimen of the lesion on the right arm was sent to biopsy (Figures 1 to 3).

Histopathological analysis revealed orthokeratosis with parakeratosis foci. The dermis showed vascular ectasia, edema, and interstitial and perivascular mononuclear infiltrate consisting of lymphocytes and histiocytes, characteristics features of histiocytoid SS (Figure 4). Initial treatment consisted of oral prednisone $40 \mathrm{mg} /$ daily) and clobetasol topical. Although lesions resolved completely, the patient kept the initial gastrointestinal complaints.
Laboratory tests revealed anemia without leukocytosis, iron deficiency, ESR $87 \mathrm{~mm} / \mathrm{h}, \mathrm{CRP} 13.9 \mathrm{mg} / \mathrm{dL}$, and nonreactive ANA test. Serology for HIV and syphilis, as well as stool and blood cultures, were negative. Colonoscopy with biopsy showed colon with loss of vascular pattern, edema, enanthem, nodules, and longitudinal ulcerations covered by fibrin with cryptitis outbreaks, and crypt abscess. Histopathological examination revealed moderate lymphocytic polymorphonuclear infiltration, corroborating the diagnosis of active pancolonic CD (Figure 5).

The patient was referred to the gastroenterology service and was treated with mesalazine $1200 \mathrm{mg}$ / daily continuing with the oral corticosteroid therapy with good clinical response. After 12 months of follow-up, intestinal symptoms remained stable and skin lesions showed no recurrence.

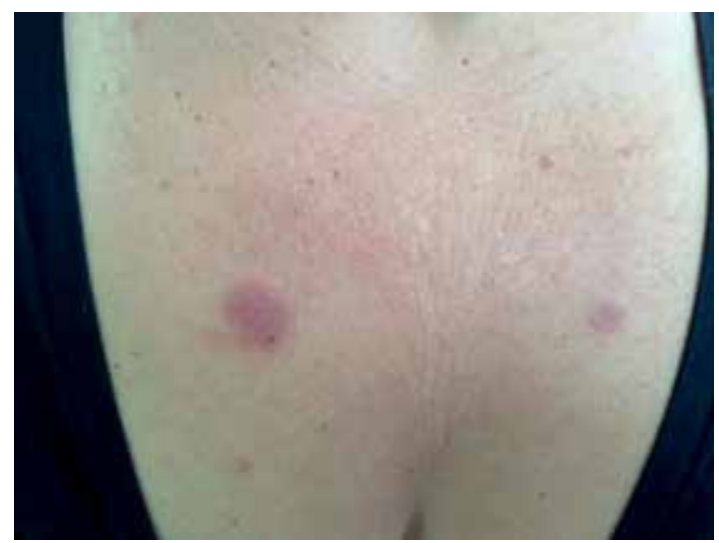

FIGURE 1: Infiltrated erythematous plaques on the anterior chest

Received on 26.10 .2015

Approved by the Advisory Board and accepted for publication on 18.01.2016

Work performed at Universidade Federal Fluminense (UFF) - Niterói (RJ), Brazil

Financial support: none.

Conflict of interest: none.

Dermatology Department at Universidade Federal Fluminense (UFF) - Niterói (RJ), Brazil.

Pathology Department at Universidade Federal Fluminense (UFF) - Niterói (RJ), Brazil.

Medical student of the Universidade do Estado do Pará (UEPA) - Belém (PA), Brazil. 


\section{DISCUSSION}

Described in 1964, Sweet's Syndrome is a neutrophilic dermatosis characterized by a range of symptoms and clinical and histological findings that include fever, neutrophilia, erythematous painful skin lesions, diffuse neutrophilic infiltration in the dermis, and rapid response to corticosteroid therapy. ${ }^{5}$ The disease is more frequent in women aged 30-60 years, in a proportion of 3.7 women per man affected. ${ }^{2}$ Based on the clinical settings in which it occurs, SS can be clas-

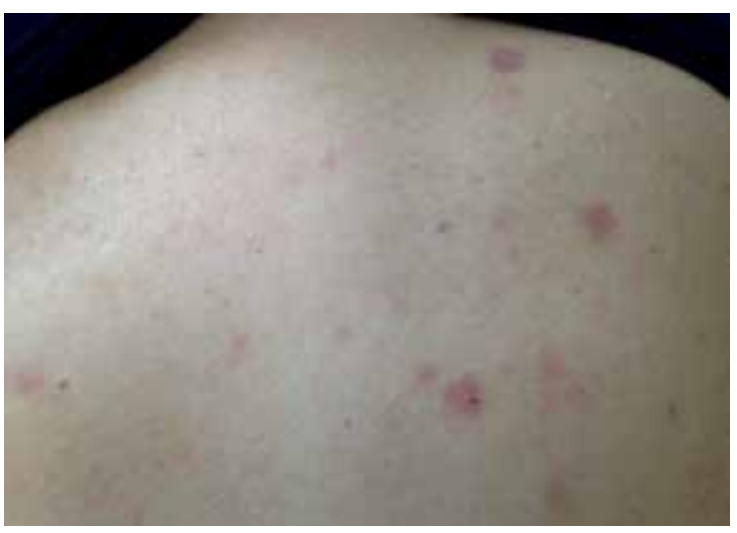

FIGURE 2: Disseminated infiltrated erythematous plaques on the upper back

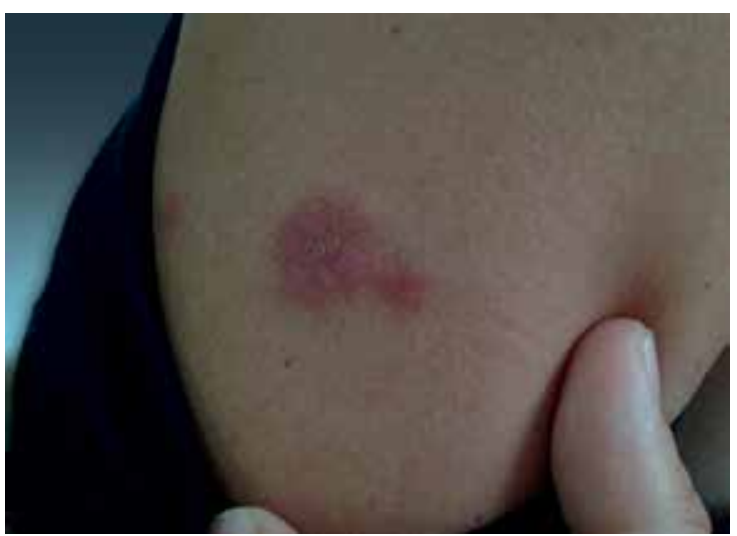

FIGURE 3: Detail of a lesion on the right arm. Infiltrated erythematous plaque with surface of pseudovesicular aspect sified into three variants: malignancy-associated SS; drug-induced SS; and classical or idiopathic SS, which is usually related to pregnancy, respiratory, gastrointestinal, or inflammatory infections. ${ }^{5}$

Clinically, classical SS appears as erythematous papular-nodular lesions, usually painful, with pseudovesicular aspect and asymmetric distribution on the face, neck and upper extrem-
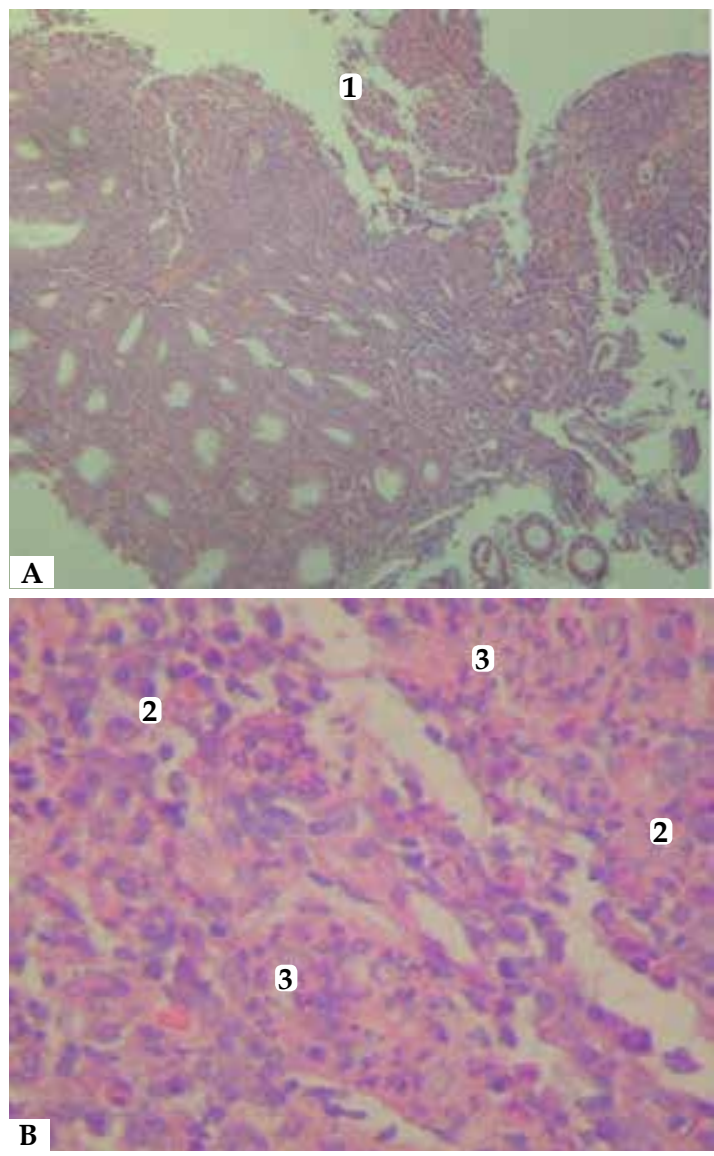

Figure 5: (A) Colonic mucosal biopsy with superficial necrosis [1] and an intense inflammatory infiltrate in the lamina propria. Glands are tortuous and have decreased mucin concentration (HE 10X). (B) Detail of mononuclear inflammatory lymphoplasmocytic infiltrate [2], with some neutrophils and crypt microabscess [3] (HE 40X).
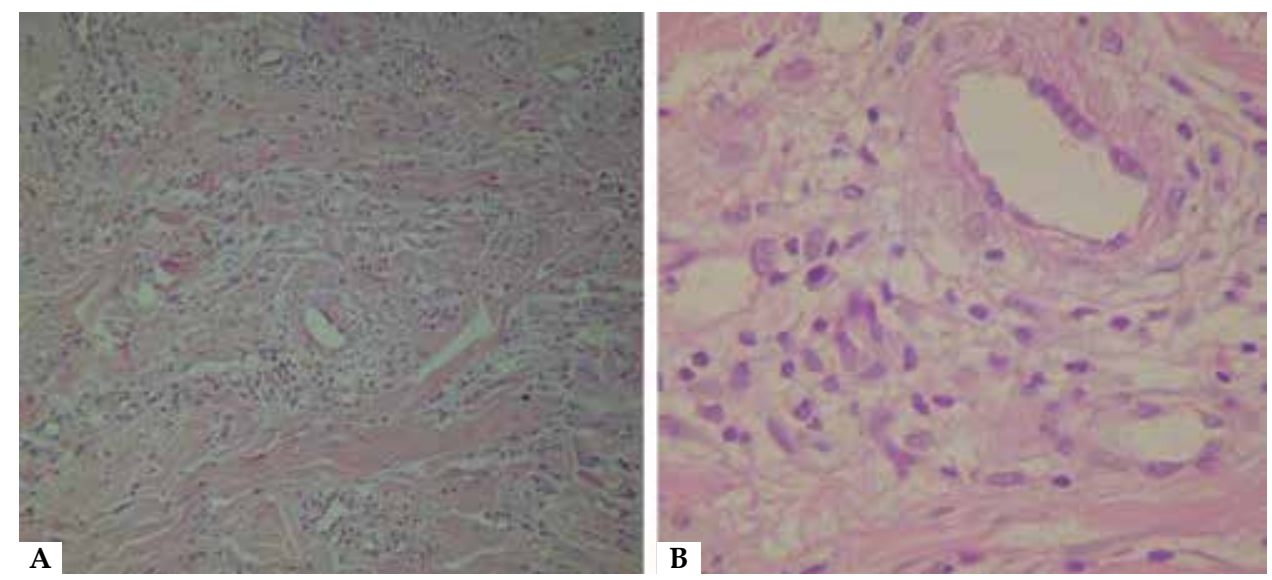

FIGURE 4: (A) Histopathological examination of skin biopsy showing interstitial mononuclear inflammatory infiltrate in the dermis (HE 20X). (B) Detail of the infiltrate of lymphocytes and histiocytes with red blood cell extravasation (HE 40X). 
ities. ${ }^{6}$ Bullous or ulcerated lesions are more frequent in malignancy-associated variants. Fever above $38^{\circ} \mathrm{C}$ is the most common sign, which may precede or occur simultaneously with skin lesions. Ocular manifestations, oral ulcers, and asymmetric oligoarthritis and polyarthritis, although less common, can also occur during the course of the syndrome. ${ }^{5}$

Histopathological examination reveals diffuse dense dermal infiltrate of neutrophils with neutrophils leukocytoclasia, but without vasculitis. Spongiosis and subepidermal blistering may occur occasionally. ${ }^{5,7}$ Histiocytoid SS has been recently described, which has identical histologic findings to SS, differing only by the presence of dermal inflammatory infiltrate consisting of immature myeloid cells. ${ }^{7}$

$\mathrm{Su}$ et al. proposed some major and minor diagnostic criteria for SS. The major criteria are the following: a) sudden onset of painful erythematous purplish plaques or nodules; and b) dense neutrophilic infiltration in the dermis with no evidence of primary leukocytoclastic vasculitis. Minor criteria are: a) fever $>38^{\circ} \mathrm{C} ; \mathrm{b}$ ) good response to systemic corticosteroids, colchicine, or potassium iodide; c) abnormal laboratory values (3 of 4): ESR $>20 \mathrm{~mm} / \mathrm{h}$, positive CRP value, Leukocytosis $>8000 / \mathrm{ml}$, and/or neutrophilia $>$ $70 \%$; d) preceded by a upper respiratory infection or associated with hematologic or visceral cancer, inflammatory disease, or pregnancy. SS diagnosis is confirmed when two major criteria and at least two minor criteria are met. ${ }^{1}$ In the present case, despite the absence of neutrophilic infiltrates in the biopsy, the patient was diagnosed with SS since all the other criteria were positive, and histopathological findings were compatible with the histiocytic variant.

\section{REFERENCES}

1. Catalán-Serra I, Martín-Moraleda L, Navarro-López L, Gil-Borrás R, Pont-Sanjuán V, Ferrando-Marco J, et al. Crohn's disease and Sweet's syndrome: an uncommon association. Rev Esp Enferm Dig. 2010;102:331-7.

2. Cohen PR. Sweet's Syndrome -a comprehensive review of an acute febrile neutrophilic dermatosis. Orphanet J Rare Dis. 2007;2:34.

3. Rappaport A, Shaked M, Landau M, Dolev E. Sweet's syndrome in association with Crohn's disease. Report of a case and review of the literature. Dis Colon Rectum. 2001;44:1526-9.

4. Pintado JCA, Doña AM, Abad AS, Lopéz AZ, García SA, Gonzalez PR et al. Síndrome de Sweet y enfermedad inflamatoria intestinal. Aportación de un nuevo caso y revisión de la literatura. An Med Interna (Madrid). 2002; 19:419-22.

5. Bonamigo RR, Razera F, Olm GS. Dermatoses neutrofilicas - Parte I. An Bras Dermatol. 2011;86:11-27.

6. Cohen PR, Kurzrock R. Sweet's syndrome revisited: a review of disease concepts. Int J Dermatol. 2003;42:761-78.

7. Requena L, Kutzner H, Palmedo G, Pascual M, Fernández-Herrera J, Fraga J, et al. Histiocytoid Sweet syndrome - a dermal infiltration of immature neutrophilic granulocytes. Arch Dermatol. 2005;141:834-42.

8. Mustafa NM, Lavizzo M. Sweet's syndrome in a patient with Crohn's disease: a case report. J Med Case Rep. 2008;2:221.

9. Gonçalves P, Miranda JS, Araújo JAM. Síndrome de Sweet e doença inflamatória intestinal - uma associação pouco frequente. Rev Soc Port Med Int. 2010;17:44-7.
The diagnosis of this condition is of great importance since it is considered a cutaneous marker of systemic diseases. Among the associated conditions, cancer is found in $25 \%$ of patients, with hematologic neoplasia being the most common. ${ }^{8}$ It may also occur in association with infections - particularly with respiratory and gastrointestinal tract infections - and autoimmune diseases such as Behçet's disease, Hashimoto's thyroiditis, and inflammatory bowel disease. ${ }^{1}$

However, concomitance with CD is rare, with only 40 cases reported in the literature. ${ }^{1}$ In general, skin lesions appear in the active phase of the disease and can, in $20 \%$ of cases, precede intestinal symptoms. In addition, other extra-intestinal manifestations may be present in patients with this association, especially joint involvement. ${ }^{1,8}$

As the spontaneous healing of lesions may take weeks to months, topical or systemic treatment is recommended, especially in very symptomatic cases or those secondary to drugs or systemic diseases. ${ }^{5,9}$ For localized lesions, high potency topical or intralesional corticosteroids are recommended. However, faced with extensive and disseminated lesions, as in the present case, in addition to treatment of the underlying disease, the therapy of choice is prednisone 0,5-1,5mg/ kg/daily, showing quick resolution. ${ }^{5}$ Other drugs, such as dapsone, potassium iodide, and colchicine, are also used, but with poor results. ${ }^{1}$

We described a case of SS in association with $\mathrm{CD}$, which deserves attention due to its rarity in clinical practice. Moreover, it is noteworthy that this dermatosis should be considered an extraintestinal manifestation of $\mathrm{CD}$, for the recognition of this association enables early diagnosis and prescription of appropriate treatment for intestinal disease, thus preventing progression to more severe clinical pictures. $\square$

\author{
MAILING ADDRESS: \\ Caren dos Santos Lima \\ Avenida Marquês de Paraná, 303 \\ Centro \\ 24033-900 - Niterói - RJ \\ Brazil \\ E-mail: caren.dossantoslima@gmail.com
}

How to cite this article: Lima CS, Pinto RDB, Góes HFO, Salles SAN, Vilar EAG, Lima CS. Sweet's syndrome associated with Crohn's disease. An Bras Dermatol. 2017;92(2):263-5. 